\title{
Erratum to: A More Reliable Method to Assess Acetabular Component Position
}

John V. Tiberi MD, Nicholas Pulos MD,

Michael Kertzner BS, Thomas P. Schmalzried MD

Published online: 31 January 2012

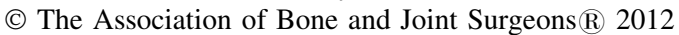

Erratum to: Clin Orthop Relat Res (2012) 470:471-476 DOI 10.1007/s11999-011-2006-8

The last name of the fourth author of this manuscript was misspelled on the article. The author's correct name is Thomas P. Schmalzried, rather than Thomas P. Schmlazried.

The online version of the original article can be found under doi:10.1007/s11999-011-2006-8.

J. V. Tiberi ( $\square)$

Department of Orthopaedic Surgery, Harbor-UCLA

Medical Center, 1000 West Carson Street,

Box 422, Torrance, CA 90509, USA

e-mail: jvtiberi@gmail.com

N. Pulos

Department of Orthopaedic Surgery, Hospital of the University

of Pennsylvania, Philadelphia, PA, USA

M. Kertzner, T. P. Schmalzried

Joint Replacement Institute at St Vincent

Medical Center, Los Angeles, CA, USA 